\title{
INTERMITTENT GASLIFT FLOWS IN VERTICAL PIPES
}

\author{
DUONG NGOC HAI \\ Institute of Mechanics, VAST \\ Nguyen Thuc Khang \\ Oil-Gas Joint Venture Vietsovpetro \\ NGUYen DuY THIEN \\ Electric Power University
}

\begin{abstract}
The paper presents the study results of intermittent gaslift vertical flows using both experiment and theoretical models. To study the influence of medium thermophysical characteristics on the process efficiency, two gas-liquid systems are used in the experiments. The obtained results show that there is a critical gas injection volume, less than that the liquid slug cannot reach the top of the tubing. Correlations for prediction of liquid entrainment in gas core are also shown for two presented gas-liquid systems. A modified dynamical model was developed. The model consists of a system of differential equations. The resulting system of equations is numerically solved. The numerical code is verified by using experimental data and calculation data of the other authors. Finally, the effects of system parameters are studied.
\end{abstract}

Keywords: intermittent gaslift, liquid-gas flows, liquid slug, physical and theoretical models, efficiency.

\section{INTRODUCTION}

A big part of all oil wells in the world is being produced using gaslift technique. Gaslift, known as continuous and intermittent lift, is realized by the injection of high pressure gas in a well, in order to create the necessary flowing bottomhole pressure to produce the desired rate of crude oil. Continuous gaslift is a direct extension of natural flow, and is accomplished by the constant gas injection at the deepest possible point in order to create the rising hydrocarbon stream. This results in reducing flowing bottomhole pressure and increasing flow from the reservoir.

Few works has been published on the intermittent gaslift. Brill et al. (1967) reported the results of a wide range of intermittent gaslift tests conducted in a $457.2 \mathrm{~m}$ height and $3.13 \div 3.81 \mathrm{~cm}$ diameter experimental well. Using experimental data, they developed an empirical "fall-back" correlation. The correlation was then used in a conceptual model of basic fluid flow equations. Neely et al. (1974) conducted field test on intermittent gaslift and correlated the average gas velocity below the liquid slug with liquid holdup predicted from continuous flow correlations. An analytical method for calculating intermittent gaslift behavior was developed that assumes a constant liquid slug velocity. Schmidt et al. (1984) presented a dynamic model for three-stage intermittent gaslift cycle 
including equations for system components in each stage, closure equations, and correlations for liquid entrainment. Application of the model to experiments with a viscous oil of 0.11 Pa.s supported the model's assumption. In Schmidt et al. method, however, it seems to be more reliable if the average tubing-casing annulus pressure is calculated by using Brill et al.'s approach because the differences between average tubing-casing annulus pressure and tubing-casing annulus pressure at gas-lift valve can be quite significant if the well depth is big. In addition, it should propose that the pressure at the top of the liquid slug would rather be determined by treating gas column above the liquid slug as a static gas column than assume it equal the separator pressure. In accordance to Gossell (1998) in oil production real conditions the obtained liquid volume will be decreased about $5-7 \%$ for 1000 feet well length.

The objects of the paper are to obtain data from tests conducted in some of conduits, to build the modified model for considered intermittent gas lift process and a computer code, developing correlations for liquid entrainment for two considered air-liquid systems, analyzing the sensitivity of system parameters by using the model and to apply for real conditions.

\section{EXPERIMENTAL STUDY}

\subsection{Experimental facilities}

The facility of experimental model for studying the intermittent gaslift consists of liquid and gas storage tanks, a test section, pressure transducers, time-valve and instruments. First, the test section was fabricated with tubes made of PVC and transparent glass. The inner diameter (ID) of the pipe is $2.5 \mathrm{~cm}$, the height of the vertical pipe $\left(Z_{p}\right)$ is 3.9 and its volume $(\mathrm{V})$ is $1.91 \times 10^{-03} \mathrm{~m}^{3}$. The second model has a height $Z_{p}=16 \mathrm{~m}$ and different inner diameter (ID $=18 ; 24$ and $30.8 \mathrm{~cm}$ ). There are three pressure transducers $P_{1}, P_{2}$, and $P_{3}$ located on the test tube: $P_{1}$ - at the height of gas lift valve position; $P_{2}$ by middle of the test tube and $P_{3}$ - on top of the test tube. They have been used to reflect value of pressure and the moving of oil and gas in the tube. Schematic diagram of the experimental facility is shown in Duong Ngoc Hai et al (2004). Liquids used in the study are refined transparent hydraulic oil (spindle oil No.10) and water. The oil has a viscosity of $8.5 \times 10^{-3} \mathrm{~Pa} . \mathrm{s}$, a density of $860 \mathrm{~kg} / \mathrm{m}^{3}$ and the oil-gas (air) surface tension of $4.5 \times 10^{-2}$ $\mathrm{N} / \mathrm{m}$; The water has a viscosity of $0.89 \times 10^{-3}$ Pa.s, a density of $980 \mathrm{~kg} / \mathrm{m}^{3}$ and the watergas (air) surface tension of $7.2 \times 10^{-2} \mathrm{~N} / \mathrm{m}$. Gas injected into the tube is provided from the large tank, which pressure $p_{t c}$ is presumed to be constant. The diameter of the gas injective hole is $10^{-2} \mathrm{~m}$ and its inclined angle in comparison with horizontal direction is $30^{\circ}$. The initial liquid slug in the test vertical pipe is $z_{i s}$. The volume of gas injected into the pipe $V_{i n}$ can be varied or keep constant by change of gas pressure $p_{t c}$ and gas injection duration. To investigate the dependence of the liquid recovery on the process parameters, many of measurements of different gas pressure, initial liquid slug, and injection time have been executed. The experiment has been carried out in the conditions of the laboratory temperature.

\subsection{Experiment results and discussion}

In general, higher liquid production $V_{p}$ can be achieved if the gas pressure $p_{t c}$, gas injected volume $V_{i n}$ and initial liquid slug $z_{i s}$ are higher. Because, in practice, the fluid accumulated time for any production well will be long if the initial liquid slug is increased. 
There is a great need for each particular well to find the reasonable initial accumulated level of liquid. A higher liquid recovery can be achieved if the gas pressure has been increased, but the expense for compressed air is increased too.

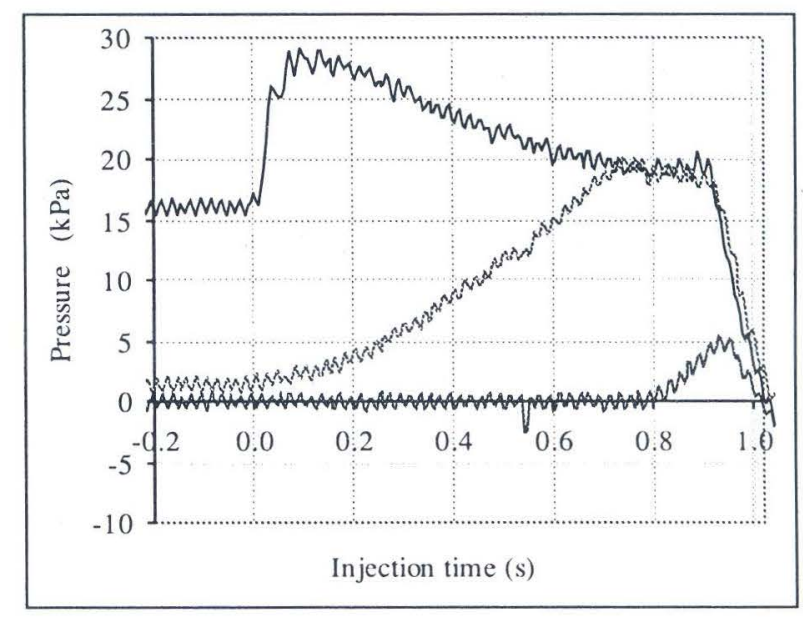

Fig. 1. Tubing pressures vs. time. (Glass tube; Spindle oil; $Z_{p}=3.9 \mathrm{~m} ; \mathrm{ID}=25 \times 10^{-3} \mathrm{~m}$ )

In Fig. 1 the pressure curves for 3 points $P_{1}, P_{2}$ and $P_{3}$ along the lift conduit are qualitatively presented. Analysing these curves we can determine the flow pattern change moments: the opened or closed moments of gas lift valve, the moment of liquid slug moving through the measurement points and the finished moments of phases. According to Fig. 1 during Phase 2, the gas pressure is higher than initial liquid pressure at conduit bottom. During this phase the pressure difference $\Delta p$ is determined mainly by liquid hydrostatic pressure, gas pressure and valve structure: $\Delta p=k\left(p_{G}-\rho g h\right)$, where $\Delta \mathrm{p}$ is a difference between before and after valve pressures; $p_{G}$ is gas tank pressure; $\rho g h$ is liquid hydrostatic pressure; $k$ is valve coefficient.

Fig. $2,4 \mathrm{a}, 5 \mathrm{a}$ show the dependence of the liquid (oil/water) production $V_{p}$ on the injected air volume $V_{i n}$, gas pressure $p_{t c}$ and different initial liquid slug $z_{i s}$. It should be noticed that the curves begin not from zero, because if the gas injected into conduit volume is too small, the liquid can not be lifted to surface and liquid received volume is zero. From Fig. 2, 4a, 5a it can be seen that received liquid volume in surface will increase if the gas injected volume increases. The increase of initial liquid height in lift conduit leads into also increase of received liquid volume in the surface.

Fig. 3, $4 \mathrm{~b}, 5 \mathrm{~b}$ show the dependence of gas oil ratio (GOR) on the dimensionless volume $V_{\text {in }} / V_{p}$ (Fig. 3) and gas volume $V_{\text {in }}$ (Fig. $4 \mathrm{~b}, 5 \mathrm{~b}$ ). According to Fig. 3, 4b, 5b, the dependence of GOR on gas injected volume $V_{i n}$ is quite different in comparison with the dependence of the received liquid volume $V_{p}$ on $V_{i n}$ presented in Fig. 3. Initially GOR is very high. If the gas injected volume is too small, GOR will be infinity (because $V_{p}=0$ ). After that this value decreases strongly and reaches the minimum point. From this point, the gas/liquid ratio will increase again, if the gas injected volume increases. From Fig. $3,4 \mathrm{~b}, 5 \mathrm{~b}$ it can be seen also that the minimum value of gas/liquid ratio will decrease, if the liquid initial height in lift conduit increases. The gas/liquid ratio GOR represents the gas volume required to lift one volume unit of liquid to the surface, so this value decrease 
means that the gas expense for lift of one liquid volume unit decreases and the process becomes more efficient.

In fact, the injected gas volume $V_{i n}$ is the most important factor. The liquid production increases while the gas volume increases, however, the growth of production is nonlinear. The rate of liquid production growth is highest at its early stage, and then it decreases. For each initial liquid slug-to-tubing string length ratio, $z_{i s} / z_{p}$, and injection pressure, Fig. 3, 4b, 5b enables us to investigate the influence of injected gas volume and to find out value, at which, GOR or expense for compressed air will be minimum. In general, this value depends on the experiment conditions, such as the injection pressure, the operation of valve, initial liquid slug length in the well, liquid properties and etc.

In accordance to experimental data, the increase of gas tank pressure leads to the decrease of liquid volume remained in the lift conduit, but it is insignificant, especially in the minimum of GOR. It may have the relationship with the liquid film thickness along the lift conduit and fall back liquid volume during the gas lift process. The remained liquid volume when gas slug reaches to end of the tube depends on characteristic of fluid (oil, water...). This volume is by $27 \%$ tube volume for oil spindle and $19 \%$ tube volume for water.

Water and spindle oil are equal density, but the viscosity of spindle oil is significant higher (about 5 times) than the viscosity of water. The liquid volume remained in lift conduit will increases if liquid viscosity increases.

\section{THEORETICAL STUDY}

The theoretical model divides the intermittent gaslift process into three stages: liquid slug rising in the tubing, liquid slug production, and liquid production by entrainment. It is assumed that the liquid slug is produced before total penetration by the injected gas occurs. To obtain the system of equations in each stage, the mass and momentum conservation equations are applied to each component of the

system. It is assumed that most of the physical variables such as density, velocity, and pressure could be replaced by their corresponding spatial average values and still reflects the behavior of the physical system with reasonable accuracy.

\subsection{Governing equations}

Equations for injected gas bubble: Mass conservation equation: Mass balance written for the volume of injected gas bubble expresses by:

$$
-\frac{d m_{t c}}{d t}=\bar{\rho}_{B} A_{B} \bar{v}_{B}
$$

where $d m_{t c} / d t$ is the mass flow rate through the gas-lift valve, $\bar{\rho}_{B}, A_{B}$ and $\bar{v}_{B}$ are the density, cross area, and rise veclocity of injected gas bubble, respectively.

Momentum conservation equation: The changes in momentum of the injected gas bubble volume caused by density and velocity changes are assumed to be negligible. In accordance with this, the momentum balance for injected gas bubble can be expressed as follows:

$$
p_{B 2}-p_{B 1}+\frac{f_{B} \bar{p}_{B} \bar{v}_{B}^{2} z_{B}}{2 d}=0,
$$

where $z_{B}, p_{B 2}$, and $p_{B 1}$ are the elevation, pressures at the top and bottom of injected gas bubble, respectively. 


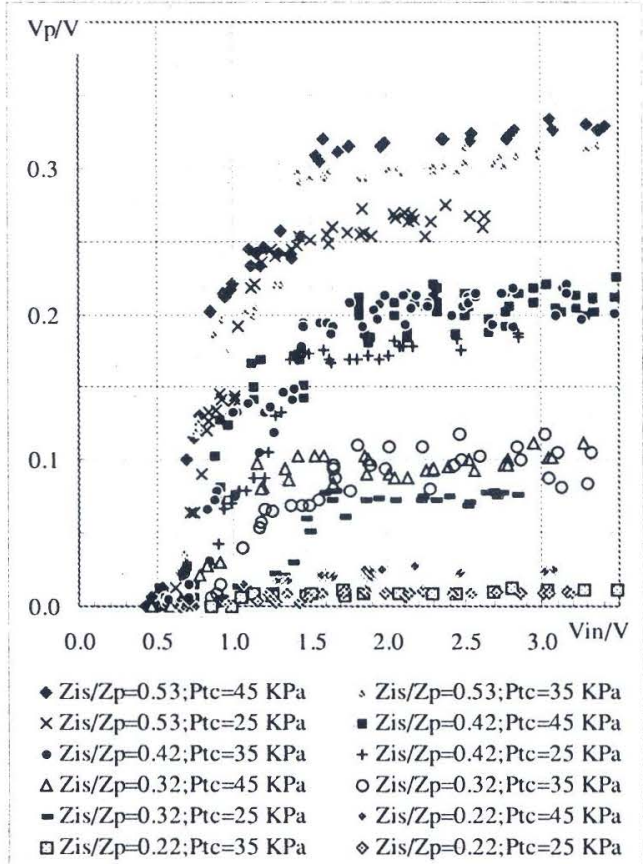

Fig. 2. The dependence of oil production $V_{p}$ on the injected gas volume Vin. (Glass, $Z_{p}=$ $3.9 \mathrm{~m}, \mathrm{ID}=25 \times 10^{-3} \mathrm{~m}, V=191 \times 10^{-3} \mathrm{~m}^{3}$ )

$\mathrm{V}_{\mathrm{p}}\left(10^{-3} \mathrm{~m}^{3}\right)$

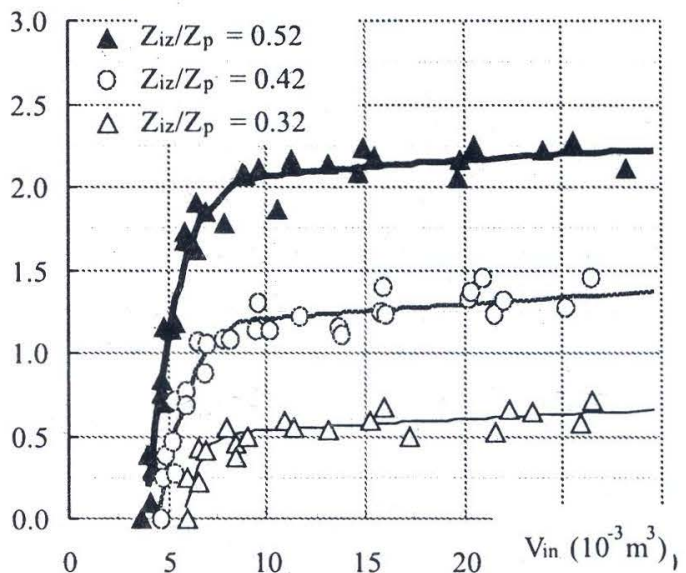

Fig. 4a. The dependence of oil production $V_{p}$ on the injected gas volume Vin. (PVC, $Z_{p}=16$ $\mathrm{m}, \mathrm{ID}=24 \times 10^{-3} \mathrm{~m}, V=7.23 \times 10^{-3} \mathrm{~m}^{3}$ )

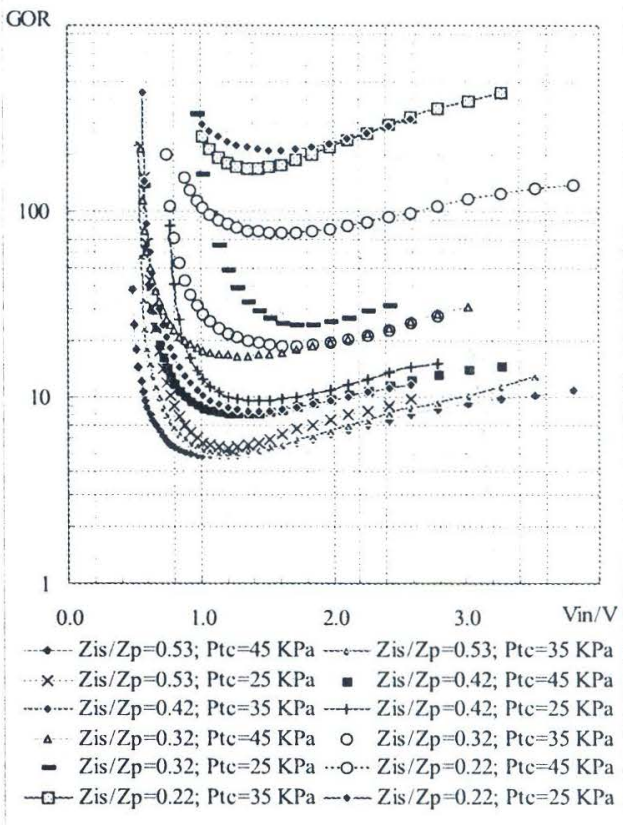

Fig. 3. The dependence of the gas-oil ratio GOR on injected gas volume Vin. (Glass, $Z_{p}=$ $3.9 \mathrm{~m}, \mathrm{ID}=25 \times 10^{-3} \mathrm{~m}, V=1.91 \times 10^{-3} \mathrm{~m}^{3}$ )

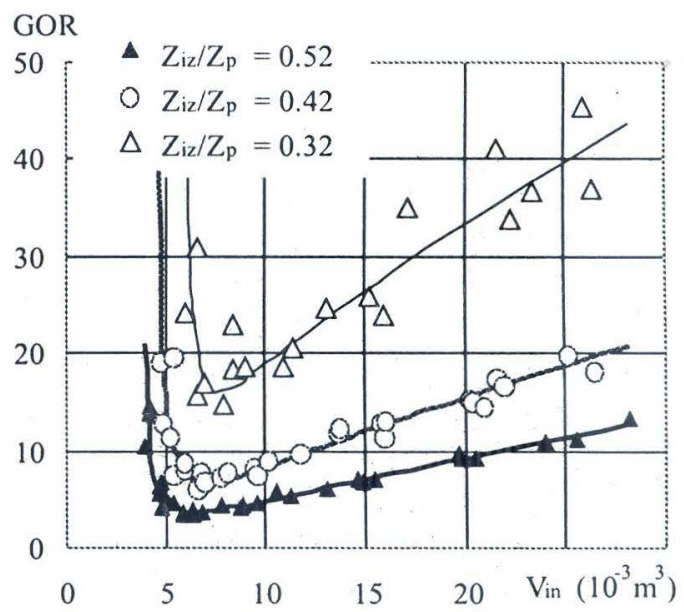

Fig. $4 b$. The dependence of the gas-oil ratio GOR on injected gas volume Vin. (PVC, $Z_{p}=16$ $\mathrm{m}, \mathrm{ID}=24 \times 10^{-3} \mathrm{~m}, V=7.23 \times 10^{-3} \mathrm{~m}^{3}$ )

Rising veclocity of the injected gas bubble $\bar{v}_{B}$ is defined by:

$$
\bar{v}_{B}=\frac{d z_{B}}{d t} .
$$




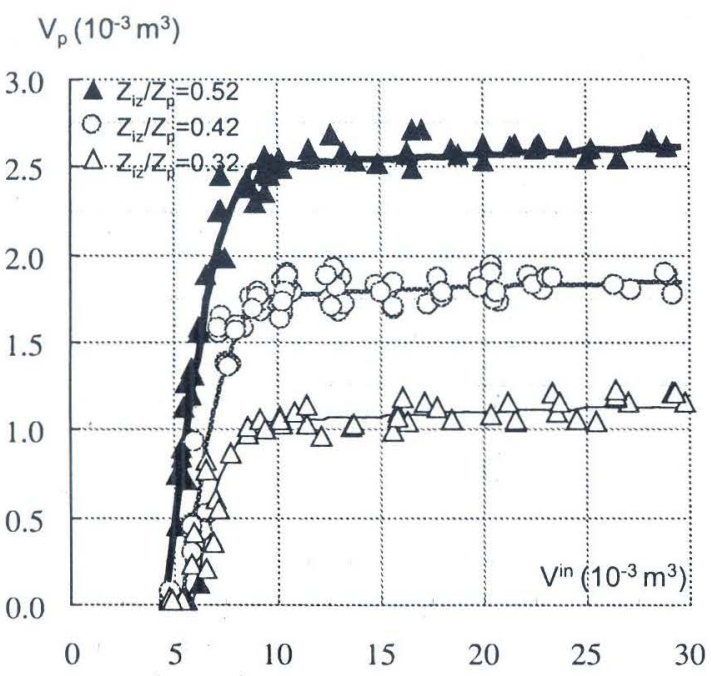

Fig. 5a. The dependence of water production $V_{p}$ on the injected gas volume $V_{i n}\left(\mathrm{PVC}, Z_{p}=16\right.$ $\mathrm{m}, \mathrm{ID}=24 \times 10^{-3} \mathrm{~m}, V=7.23 \times 10^{-3} \mathrm{~m}^{3}$ )

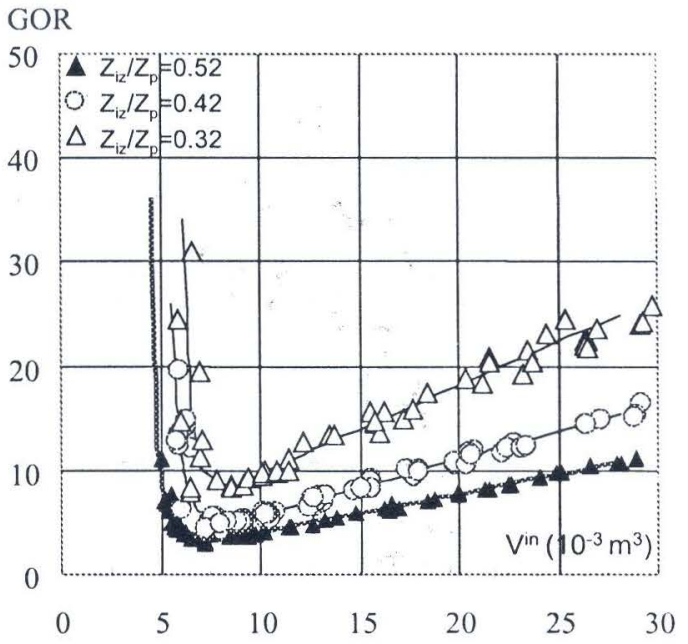

Fig. 5b. The dependence of the gas-water ratio GOR on injected gas volume $V_{i n}$. (PVC, $Z_{p}=16$ $\mathrm{m}, \mathrm{ID}=24 \times 10^{-3} \mathrm{~m}, V=7.23 \times 10^{-3} \mathrm{~m}^{3}$ )

The bubble friction factor $f_{B}$ that incorporates liquid entrainment effects is determined by experimental function of liquid film thickness $y_{B}$ and tubing diameter $d$, which was developed based on the experimental results:

$$
f_{B}=0.059\left(1+111.8 \frac{y_{B}}{d}\right),
$$

for a 0.1 Pa.s oil - air system (Schmitd et al., 1984), and

$$
f_{B}=0.005\left(1+298 \frac{y_{B}}{d}\right)
$$

for water - air system (Wallis, 1969).

Equations for liquid films:

It should be noted that the major mechanism for liquid production from the liquid film is entrainment of liquid into the moving gas core rather than from a moving liquid film. Observations of Schmidt et al. carried out in the test facility confirmed that after the liquid slug has passed, the film velocity is indeed very small. Assuming the liquid film from an elevation $z *$ to the bottom of the liquid slug $z_{B}$ moves at average-velocity $\bar{v}_{F}$ and the film velocity at $z *$ and lower is zero. The mass balance written for the part of liquid film between $z *$ and $z_{B}$ gives the following relationship between $\bar{v}_{F}$ and the rate of change of film thickness $d y_{B} / d t$ :

$$
\rho_{L} \bar{v}_{F}\left(A-A_{B}\right)+\rho_{L} \frac{d y_{B}}{d t} \pi\left(d-2 y_{B}\right)\left(z_{B}-z^{*}\right)=0,
$$

where $\rho_{L}$ is the liquid density, and $A_{B}$ is determined by following expression:

$$
A_{B}=\pi \frac{\left(d-2 y_{B}\right)^{2}}{4} \text {. }
$$

Equations for liquid slug: 
Mass conservation equation: Before the bottom of the liquid slug reaches the surface, mass balance can be written as:

$$
\bar{v}_{L} A-\bar{v}_{B} A_{B}-\bar{v}_{F}\left(A-A_{B}\right)=0,
$$

where $\bar{v}_{L}$ is the average liquid veclocity.

$$
\begin{aligned}
& \rho_{L} \frac{d \bar{v}_{L}}{d t} A\left(z_{L}-z_{B}\right)+\rho_{L} \bar{v}_{L}^{2} A-\rho_{L} \bar{v}_{B}^{2} A_{B}-\rho_{L} \bar{v}_{F}^{2}\left(A-A_{B}\right)+ \\
& \left(p_{t s}-p_{B 2}\right) A+\rho_{L} g A\left(z_{L}-z_{B}\right)+f_{L} \frac{\rho_{L} \bar{v}_{L}^{2} A\left(z_{L}-z_{B}\right)}{2 d}+H_{w}=0,
\end{aligned}
$$

where $H_{w}$ is the pressure loss caused by the right-angle bend in the tubing at the surface and

$$
\bar{v}_{L}=\frac{d z_{L}}{d t} .
$$

The liquid friction factor $f_{L}$ is the standard Moody friction factor given by

$$
f_{L}=f_{L}\left(N_{L}, \frac{\varepsilon}{d}\right)
$$

where $\varepsilon$ is tubing roughness, and $N_{L}$ Reynolds number is determined by

$$
N_{L}=\frac{\rho_{L} \bar{v}_{L} d}{\mu_{L}} .
$$

Equations for liquid entrainment:

After the liquid slug is produced, in order to close the model, it is necessary to determine the mass transfer between the injected gas and liquid film in dependence on process parameters. An empirical method originally proposed by Hughmark (1973) for liquid-air systems is the consideration of liquid entrainment rate as a function of gas velocity and film thickness. Schmidt et al. based on this method also received the correlation for system of oil viscosity of $1.0 \times 10^{-1} \mathrm{~Pa} . \mathrm{s}$ and air. The empirical correlations are given by:

$$
\begin{aligned}
& \left\{\begin{array}{ll}
y_{B}^{+}<36, & \alpha=0 \\
36<y_{B}^{+}<42, & \alpha=-0.000442+1.3 .10^{-5} y_{B}^{+} \\
42<y_{B}^{+}<60, & \alpha=-0.000625+1.72 .10^{-5} y_{B}^{+} \\
y_{B}^{+}>60, & \alpha=5.0 .10^{-8}\left(y_{B}^{+}\right)^{2.2}
\end{array} \quad \text { for } \quad \mu_{L}<5.0 \times 10^{-3}\right. \text { Pa.s } \\
& \alpha=1.202 .10^{-5}\left(y_{B}^{+}\right)^{1.51} \text { for } \mu_{L}=1.0 \times 10^{-1} \text { Pa.s, }
\end{aligned}
$$

where $\alpha=W_{E} \bar{\rho}_{B} / W_{B} \rho_{L}$ is the liquid to gas phase volumetric velocity ratio. The dimensionless film thickness $y_{B}^{+}$is defined by:

$$
y_{B}^{+}=\frac{y \sqrt{\frac{\left(\tau_{w}+\tau_{i}\right) \bar{\rho}_{B}}{2}}}{\mu_{B}},
$$

where $\mu_{B}=\mu_{L}^{\chi_{L}} \mu_{g}^{1-\chi_{L}}$ is the viscosity of gas core; $\chi_{L}$ is volumetric liquid fraction; $\tau_{w}, \tau_{i}$ are the wall and interface shear stresses:

$$
\begin{gathered}
\tau_{w}=-\left[\frac{p_{B 2}-p_{B 1}}{z_{B}}+g \rho_{L}\left(1-\frac{A_{B}}{A}\right)+\bar{\rho}_{B} g \frac{A_{B}}{A}\right] \frac{d}{4}, \\
\tau_{i}=-\left[\frac{p_{B 2}-p_{B 1}}{z_{B}}+\bar{\rho}_{B} g\right] \frac{d-2 y}{4}
\end{gathered}
$$


The entrained mass flow rate $W_{E}(z, t)$ is related to the rate of liquid film loss by the equation of mass conservation for any fixed segment of the tubing string from $z_{1}$ to $z_{2}$ :

$$
\frac{d}{d t}\left[\frac{W_{E}\left(z_{2}\right)}{\bar{v}_{E}\left(z_{2}\right)}\right]\left(z_{2}-z_{1}\right)+W_{E}\left(z_{2}\right)-W_{E}\left(z_{1}\right)+\frac{d m_{F}}{d t}=0
$$

where $m_{F}$ is the mass of the liquid film from tubing string elevation $z_{1}$ to $z_{2}$ :

$$
m_{F}=\rho_{L}\left(\pi d^{2}-\pi\left(d-2 y\left(z_{2}\right)\right)^{2}\right) \frac{\left(z_{2}-z_{1}\right)}{4} .
$$

Equations for tubing-casing annulus:

The time dependence of tubing-casing annulus pressure is essential for describing gas passage through the operating gas-lift valve. The ideal situation is to have the recording at the position opposite to the gas-lift valve. However, in field conditions, this is not realizable, and the recording is usually written at the surface. In this case, we have to use this record for calculating gas pressure at gas-lift valve. An approach can be used to extend the surface tubing-casing annulus pressure to gas-lift valve by treating it as a static gas column. Having the tubing-casing annulus head pressure recording, $p_{c h}$, the pressure at the operating gas-lift valve can then be calculated by using a static gas column equation:

$$
p_{C V}=p_{c h} e^{\frac{M g z g v}{\bar{Z}_{t c} R T}}
$$

where $g$ is gravity acceleration, $R$ is the gas constant, $M$ is the gas molecular weight, $T$ is temperature, $\bar{Z}_{t c}$ is gas compressibility factor in tubing-casing annulus and $z_{g v}$ is gaslift valve depth.

Equation for gas column above the liquid slug:

The pressure at the gas-liquid interface at the top of the slug is composed of the surface tubing pressure and the pressures due to gas column weight and viscous drag in the gas phase above the slug. The viscous drag forces are assumed to be negligible here as they are in the tubing-casing annulus. Assuming that a constant wellhead pressure equal to the separator pressure, the pressure at the top of the liquid slug becomes

$$
p_{t s}=p_{s p} e^{\frac{M g z L}{\bar{Z}_{w h} R T}},
$$

where $\bar{Z}_{t c}$ is gas compressibility factor in tubing string and $z_{L}$ is the depth of the top of liquid slug.

Closure equations:

In order to complete the model, certain closure relationships for process parameters must be obtained. These closure relationships are as follows:

Gas state equation:

$$
\frac{p_{B 1}+p_{B 2}}{2}=\bar{\rho}_{B} \frac{\bar{Z}_{B} R T}{M}
$$

gives the relationship between the average bubble pressure and density, and

$$
\bar{p}_{t c}=\bar{\rho}_{t c} \frac{\bar{Z}_{t c} R T}{M}
$$

where $\bar{p}_{t c}, \bar{\rho}_{t c}$ are average pressure and average density, respectively; $\bar{Z}_{B}$ is the gas compressibility factor in tubing string, gives the relationship between the average tubing-casing 
annulus pressure and density.

$$
\begin{gathered}
\frac{d m_{t c}}{d t}=-\frac{\pi \sqrt{2}}{4} \frac{C Y D^{2}}{\sqrt{1-\beta^{4}}} \sqrt{\bar{\rho}_{t c}\left(\bar{p}_{t c}-p_{B 1}\right)}, \\
\bar{v}_{B}=a \bar{v}_{L}+b .
\end{gathered}
$$

Collins et al. (1978) have theoretically analyzed the motion of large gas bubble rising in a liquid and proposed expressions for the coefficients a and b in terms of the liquid Reynolds number:

$$
\begin{gathered}
a=\frac{\log R e_{L}+0.089}{\log R e_{L}-0.74} \\
b=\sqrt{g d}\left\{\left[\frac{\bar{v}_{L}}{\sqrt{g d}} \frac{0,083}{\log R e_{L}-0,74}\right]^{1 / 3}+\frac{1}{3}\left[\frac{\bar{v}_{L}}{\sqrt{g d}} \frac{5,84}{\log R e_{L}-0,74}\right]^{-1 / 3}\right\} .
\end{gathered}
$$

\subsection{Equations governing the physical system before slug production}

25 independent equations, equations (3.1)-(3.25), are used for the description of this stage of production cycle. In total 25 unknowns they are as follows:

$$
\begin{aligned}
& a, b, \bar{v}_{F}, \bar{v}_{L}, \bar{v}_{B}, N_{L}, p_{B 1}, p_{B 2}, p_{t s}, p_{C V}, \bar{p}_{t c}, \bar{\rho}_{B}, \bar{\rho}_{t c}, \\
& \tau_{i}, \tau_{w}, y_{B}, A_{B}, m_{F}, f_{L}, f_{B}, z_{L}, z_{B}, m_{t c}, y_{B}^{+}, W_{E} .
\end{aligned}
$$

\subsection{Equations governing the physical system during slug production}

23 independent equations (3.1)-(3.8), (3.10)-(3.18) and (3.19)-(3.25) are valid for this stage. But during this stage, it should be put: $z_{L}=z_{p}$ and $p_{T S}=p_{s p}$. In this case, the unknowns totally 23 are as follows:

$$
\begin{aligned}
& a, b, \bar{v}_{F}, \bar{v}_{L}, \bar{v}_{B}, N_{L}, p_{B 1}, p_{B 2}, p_{C V}, \bar{p}_{t c}, \bar{\rho}_{B}, \bar{\rho}_{t c} \\
& \tau_{i}, \tau_{w}, y_{B}, A_{B}, m_{F}, f_{L}, f_{B}, z_{B}, m_{T C}, y_{B}^{+}, W_{E} .
\end{aligned}
$$

\subsection{Equations governing the physical system after slug production}

Only 14 equations (3.1), (3.2), (3.4), (3.6), (3.12)-(3.18), and (3.20)-(3.22) are used for this stage. During this stage, we have: $z_{B}=z_{p}$ and $p_{B 2}=p_{s p}$. In this case, the unknowns are as follows: $\bar{v}_{B}, p_{B 1}, p_{C V}, \bar{p}_{t c}, \bar{\rho}_{B}, \bar{\rho}_{t c}, \tau_{i}, \tau_{w}, A_{B}, m_{F}, f_{B}, m_{t c}, y_{B}^{+}, W_{E}$, which in total are 14 .

\subsection{Numerical model}

Solution method of model equations:

The above presented system of equations were obtained using the following assumptions: No slippage between the moving gas core and the entrained liquid: $\bar{v}_{E}=\bar{v}_{B}$ and no liquid flows into the tubing from the reservoir during gas injection: $W_{E}(0, t)=0$. The system of governing equations for each stage of the intermittent gas-lift is nonlinear and is solved numerically by using standard techniques for each time step. The liquid entrainment is calculated by integrating Eq. (3.16) with taking into account of Eৃqs. (3.12)-(3.15), and Eq. (3.17). This is carried out by dividing the tubing string into a number of segments, each of which is with its own film thickness, after that solving Eq. (3.16) for each segment, starting from $\mathrm{z}=0$ and finishing at the segment $z *$. The film thickness is found for each segment and each time step, and the value $z *$ is replaced into Eq. (3.5). A computer program in Fortran language was built to implement above described procedure. 


\section{Model validation:}

For validation, the calculation results of liquid slug velocity, slug production time, and liquid production are compared to the experimental and calculated data of Schmitd et al. (1984). The tubing string has an inside diameter of $0.076 \mathrm{~m}$ and a length of $18.0 \mathrm{~m}$. For all the tests, initial liquid slug length is $9.0 \mathrm{~m}$ and the choke diameter is $0.025 \mathrm{~m}$. Tubing-casing annulus volume is $1.2 \mathrm{~m}^{3}$. The following fluid properties are used in the numerical simulation: liquid density $\rho_{L}=876.0 \mathrm{~kg} / \mathrm{m}^{3}$, gas density $\rho_{L}=1.226 \mathrm{~kg} / \mathrm{m}^{3}$, liquid viscosity $\mu_{L}=0.11 \mathrm{~Pa} . \mathrm{s}$, gas viscosity $\mu_{g}=0.19 \times 10^{-4}$ Pa.s. Average temperature of $16^{\circ}$ C $(289 \mathrm{~K})$ in both tubing-casing annular and tubing string were used. The comparisons between the predicted and experimental liquid slug velocity, slug production time, and liquid production are illustrated in Figs. 6-9.

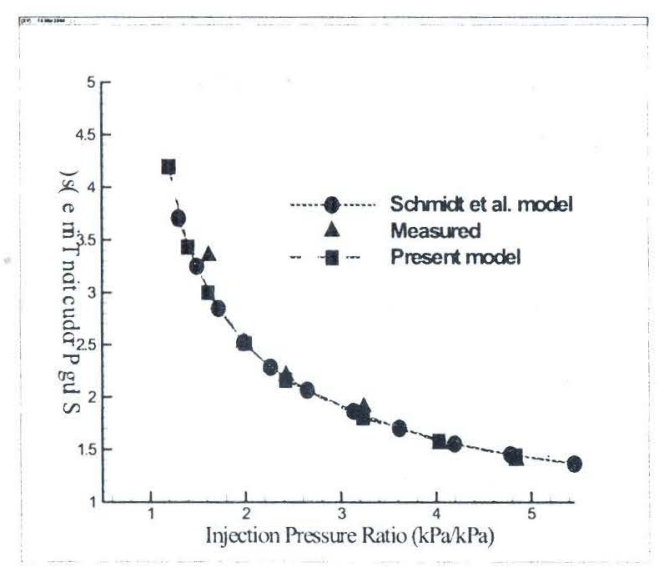

Fig. 6. Slug production time vs. injection pressure ratio

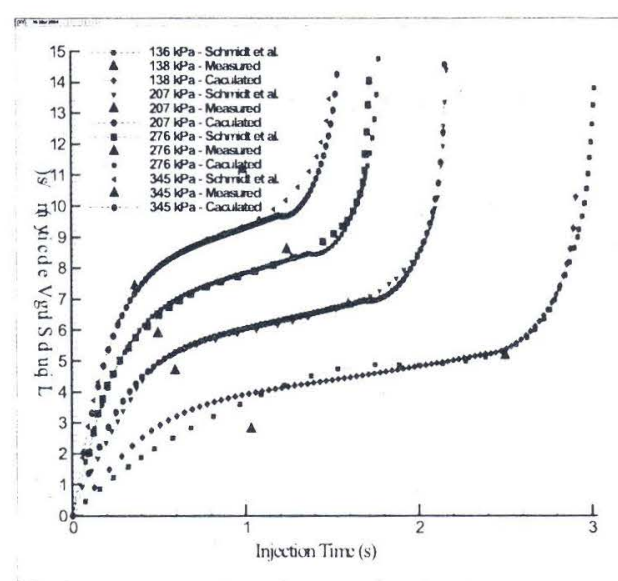

Fig. 7. Liquid slug velocity vs. time

Fig. 6 shows the comparison between the present model calculations and the calculations of Schmidt et al. for the slug production time. Reasonable agreement is obtained over the entire range of injection pressure ratios considered, $p_{t c} / p_{B 1}$. From Fig. 6 , it can also be seen that the slug production time is decreased with an increase of injection pressure as expected.

Fig. 7 shows comparisons the predictions of the present model with predictions of Schmidt et al. (1984) and measured data for liquid slug velocity. It can be seen that the liquid slug velocity curves for three higher different injection pressures predicted by the present model are similar to the calculated results of Schmidt et al. and the measured data not only in shape but also in magnitude. The characteristics of these curves are: rapidly initial acceleration (start-up); a leveling off of the velocity (close to steady); and then rapid acceleration again as the liquid slug is produced at the surface. There is a discrepancy between the liquid slug velocity curves for low injection pressure of $207 \mathrm{kPa}$. This discrepancy may be caused by lack of precise information of input data such as discharge coefficient, gas viscosity, gas density, which are not fully described in the paper of Schmidt et al.

The present model predictions for total liquid production by slug and by entrainment are agreed well with results calculated by Schmidt et al. model for two injection pressure 
ratios (Fig. 8) and measurement data (Fig. 9). It can be seen that the liquid recovery increases with the increase of injection time. Prolonging injection beyond 20 seconds results in little extra production. The ultimate recovery is the same for both injection pressure ratios. If the injection pressure is increased, a higher recovery can be achieved more rapidly, but only with the increase of injected gas.

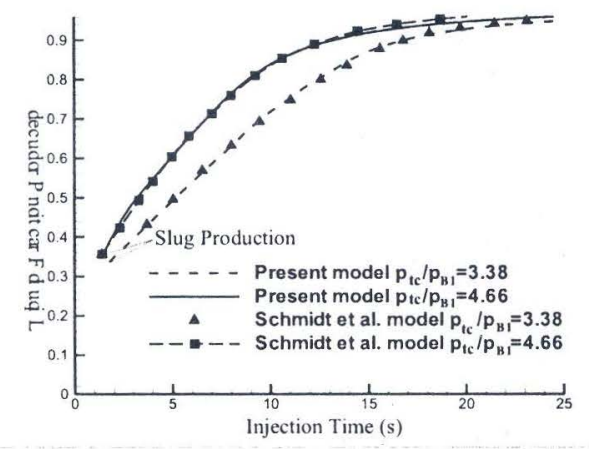

Fig. 8. Liquid production vs. injection time

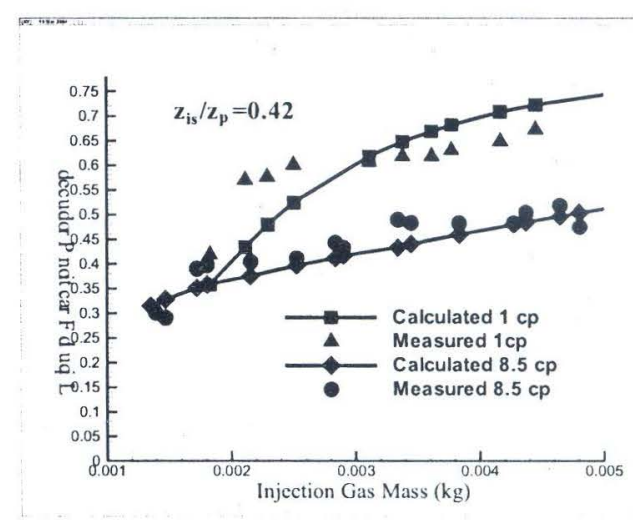

Fig. 9. Liquid production vs. injection gas mass

\subsection{Development of correlations for liquid entrainment}

For most mechanistic models of multiphase flows, usually one or more empirical closure relationships are required. In the presented above model, we need to determine the liquid entrainment rate. Using the numerical program and the experimental data presented in Section 2, we can develop this correlation for systems of spindle oil 10-air and water-air in the form of $\alpha=a\left(y_{B}^{+}\right)^{b}$.

In this case, the equation $(3.4 \mathrm{~b})$ is used for bubble friction factor. The coefficients $a$ and $b$ are determined so that the calculated and measured liquid recoveries (Fig. 10) are reasonably agreed each with other. The $\alpha$ values obtained in this study are plotted in Fig. 14 as function of the dimensionless film thickness: $\alpha=1.20 \times 10^{-5}\left(y_{B}^{+}\right)^{1.9}$ for water-air system, and $\alpha=1.05 \times 10^{-5}\left(y_{B}^{+}\right)^{1.6}$ for spindle oil $10\left(8.5 \times 10^{-3} \mathrm{~Pa} . \mathrm{s}\right)$ - air system.

\subsection{Model analysis}

\section{Sensitivities analysis:}

After being validated, the numerical code was used for sensitivity analysis of different operating parameters. Initial liquid slug length $z_{i s}$ and injection pressure $p_{t c}$ are two main control parameters that affect the behavior of intermittent gas lift process. Other parameters can affect the behavior of intermittent gas lift process too, but they usually do not offer ample opportunity for control. These parameters are: casing diameter, tubing string diameter, well perforation depth, tubing string length, fluid properties, reservoir pressure, wellhead pressure. The following sections describe some of these studies providing some inside views of dynamics of the intermittent gaslift.

* Effect of injection pressure and initial liquid slug length: It is desirable to produce the liquid in a slug form as much as possible because the ratio of total gas volume injected per volume of liquid produced GOR, as shown in Fig. 10, is rapidly increased after gas breaks through the liquid slug. 


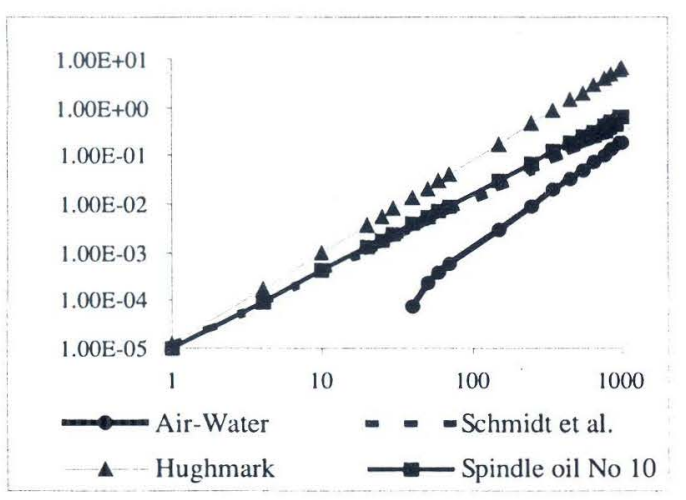

Fig. 10. Liquid entrainment vs. dimensionless film thickness

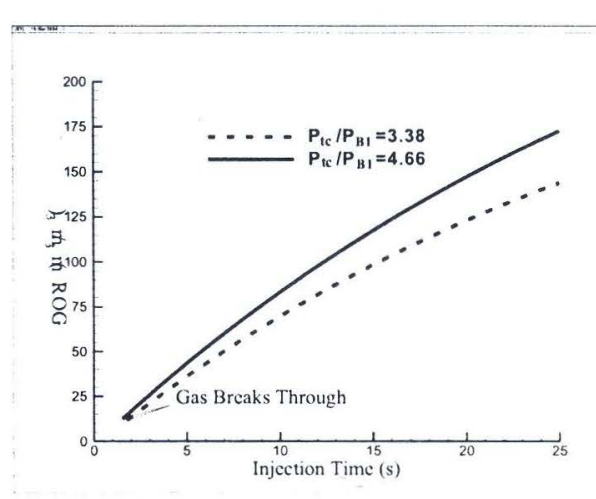

Fig. 11. Liquid entrainment vs. dimensionless film thickness

Fig. 11 shows how the injection pressure and initial liquid slug length affect on the liquid production by slug in a cycle. The same trend would exist for all the initial liquid slug lengths. An increase in initial liquid slug length and injection pressure results in increasing in liquid recovery. There is a qualitative agreement between the curves presented in Fig. 11 and measured data, as shown in Fig. 1. It should be emphasized that the total production per day depends on not only the total liquid production per cycle but also the number of cycles per day. Therefore, an increase in liquid recovery per cycle cannot yet conclude that it is more efficient on daily. The increase in production per cycle could reduce the number of cycles per day. In order to able to optimize an intermittent gaslift system, it is necessary to combine the present model with a liquid-accumulated model. From the calculation results, it should be noticed that for each ratio of $z_{i s} / z_{p}$, there exists an injection pressure ratio at which the liquid slug can not lifted to the surface and a short range of the injection pressure ratio in which liquid recovery is swiftly increased. Injection pressure ratio which exceeds this range only yields a small additional production.

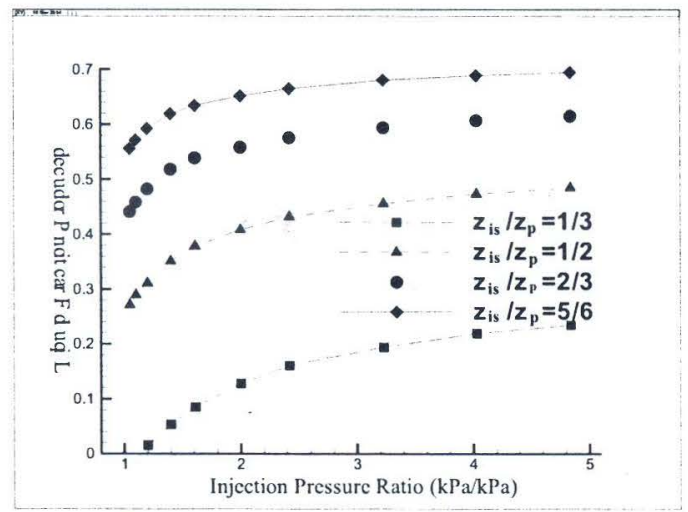

Fig. 12. Slug production vs. injection pressure ratio

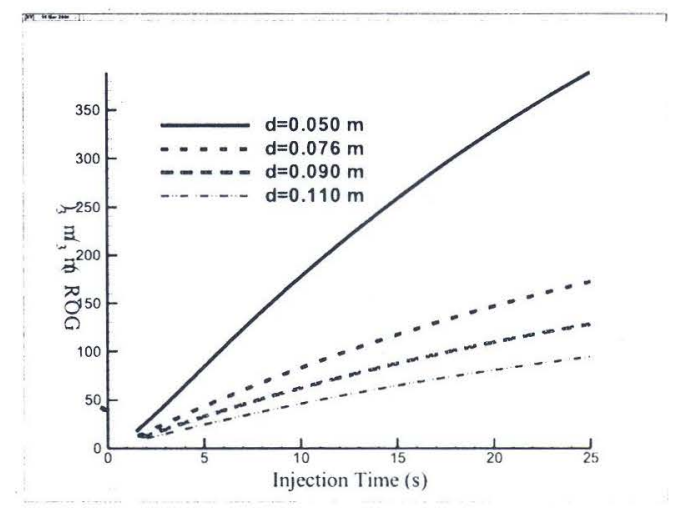

Fig. 13. Production GOR vs. injection time, sensitivity parameter: tubing diameter

Fig. 2 shows the influence of injection pressure ratio on GOR, in which GOR curve for a small ratio $z_{i s} / z_{p}$ of $1 / 3$ is not shown because of its too big values. An agreement in 
trend with experimental results was also found (see Figs. 2, 4). It is interesting to note that for each ratio of $z_{i s} / z_{p}$ there exists an injection pressure ratio giving a minimum GOR. The GOR minimum predicted by the calculations are occurred at the injection pressure ratios of $4.03: 1 ; 1.4: 1.0 ; 1.1: 1.0$; and $1.05: 1.0$ for $z_{i s} / z_{p}=1 / 3 ; 1 / 2 ; 2 / 3$ and $5 / 6$, respectively.

* Effect of tubing string diameter: For the given valve port size and initial tubingcasing annulus pressure, a higher liquid production can be obtained more quickly by using smaller tubing (Fig. 13). However, using small tubing is not efficient because of several following reasons. First, small tubing offers more friction resistance to flow, and also reduce the liquid volume lifted per a cycle. For example, after injection duration of 5 seconds, the liquid volume lifted per a cycle by using a tubing diameter of $0.05 \mathrm{~m}$ is smaller 0.34 times in comparing to that of tubing diameter of $0.11 \mathrm{~m}$ even if production liquid fraction achieved by using a tubing diameter of $0.05 \mathrm{~m}$ is much higher than that by a tubing diameter of $0.11 \mathrm{~m}$. Second, GOR by using small tubing is much higher than that by using large tubing. It is clearly shown in Fig. 13 that after an injection time of 5 seconds, using a tubing diameter of $0.005 \mathrm{~m}$, GOR is about $84 \mathrm{~m}^{3} / \mathrm{m}^{3}$ while using of a tubing diameter of $0.11 \mathrm{~m}$, GOR is only about $24 \mathrm{~m}^{3} / \mathrm{m}^{3}$.

* Effect of tubing roughness: Calculation results indicated that before slug is produced at the surface, the effect of tubing roughness on liquid slug velocity is relatively insignificant. When slug is produced at the surface, the weight of liquid slug will decrease and this causes an acceleration of liquid slug. As a result, this effect is a little larger. However, total liquid production is not much affected by the tubing roughness.

Calculation for real condition:

Figs. 14-17 show the calculation results for real condition, namely, when vertical well has the length of $\sim 3200 \mathrm{~m}$ and the reservoir pressure $\operatorname{Pr}$ is 182 at. The gaslift valve is installed at the depth of $2899 \mathrm{~m}$. The fluid - the mixture of crude oil and water - has a density of $560 \mathrm{~kg} / \mathrm{m}^{3}$ (at standard condition), the viscosity of $10.1310^{-3} \mathrm{~Pa} . \mathrm{s}$ at $\mathrm{T}=50$ ${ }^{0} \mathrm{C}$ and $1.17810^{-3}$ Pa.s at $\mathrm{T}=137{ }^{0} \mathrm{C}$. The gas density is $0.975 \mathrm{~kg} / \mathrm{m}^{3}$ and adiabatic coefficient is 1.256. The gas regimes with $27800 ; 12500 ; 6900$ and $3200 \mathrm{~m}^{3} /$ days are in accordance with cases of the initial liquid heights of $400 ; 600 ; 800$ and $1000 \mathrm{~m}$ or $\mathrm{Pb} 1 / \mathrm{Pr}$ $=0.223 ; 0.285 ; 0.350$ and 0.410 ( $\mathrm{Pb} 1$ - liquid static pressure at initial moment of cycle) respectively. The well incline angle is 16 degrees. The surounding temperature at valve installed position is $97^{\circ} \mathrm{C}$ and surrounding surface temperature is $32^{\circ} \mathrm{C}$.

The investigation results presented in Figs. 14-17 show that using the model calculation the appropriate gas injection regimes can be chosen for maximum received liquid or for avoiding the asphalt-paraffin deposition on well wall due to temperature decreasing.

\section{CONCLUSIONS}

Based on the physical model, the data sets for intermittent gaslift were obtained for two gas-liquid systems. The data sets were used to develop new correlation of liquid entrainment functions. A modified dynamic model was developed for intermittent gaslift. Based on the model, the numerical code was built and verified by experimental data and calculation data of the other authors. For each initial liquid slug length, there exists a ratio of casing-tubing pressure to tubing string pressure at which liquid slug can not lifted to the surface and a ratio of casing-tubing pressure to tubing string pressure at which the minimum GOR will occur. If initial liquid slug length - tubing length ratio is small (less 


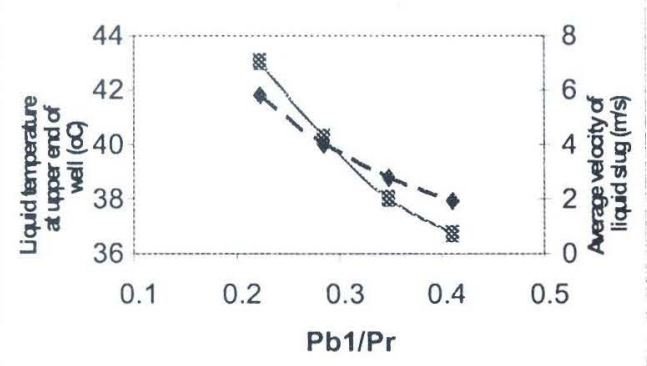

Liquid temperature at upper end of well (OC)

- Average velocity of liquid slug $(\mathrm{m} / \mathrm{s})$

Fig. 14. Liquid temperature at upper end of well and liquid slug average velocity vs. $\mathrm{Pb} 1 / \mathrm{Pr}$

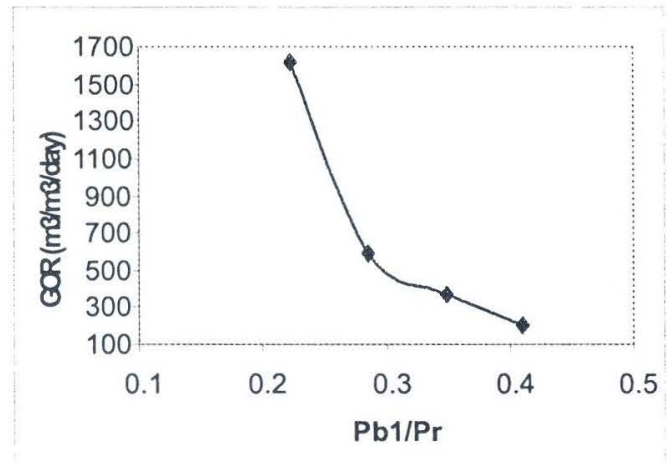

Fig. 16. Dependence of GOR on $\mathrm{Pb} 1 / \mathrm{Pr}$

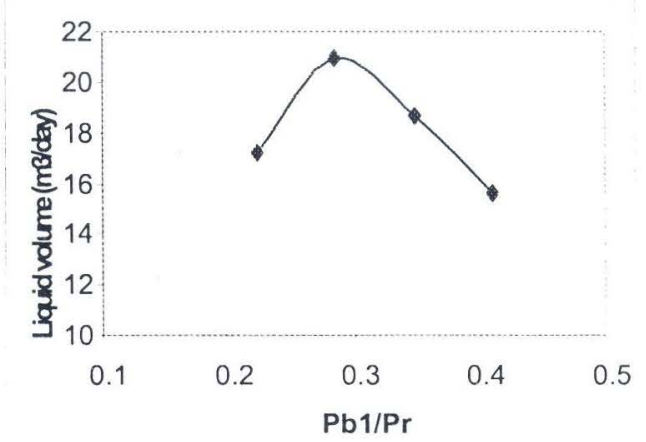

Fig. 15. Received liquid volume vs. $\mathrm{Pb} 1 / \mathrm{Pr}$

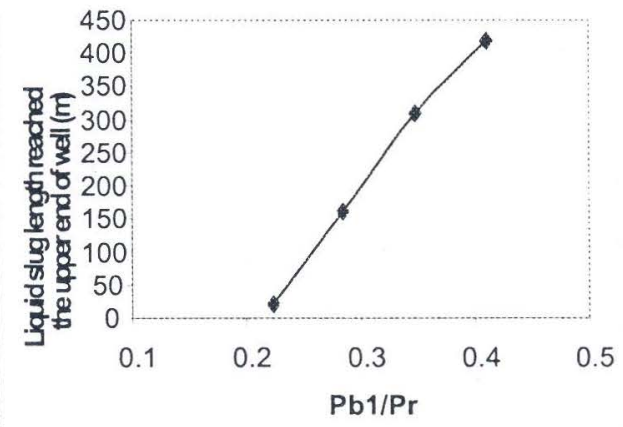

Fig. 17. Liquid slug length reached upper end of well vs. $\mathrm{Pb} 1 / \mathrm{Pr}$.

than 1.3), the intermittent gaslift operation is not efficient. The tubing diameter plays an important role. The larger tubing is, the higher liquid production can be achieved. Tubing roughness has a small effect on the intermittent gaslift. The calculation results for real condition show the effectiveness of the mathematical model. The data sets and model presented in the paper can be used for analyzing different situations which could be occurred in gaslift practices.

Acknowledgements. The investigation is implemented with partly financial support from the Vietnam National Fund of Fundamental Research.

\section{REFERENCES}

1. J. P. Brill, T. C. Doerr and K. E. Brown, An Analytical Description of Liquid Slug Flow in Small-Diameter Vertical Conduits, J. Pet. Tech. 19 (1967) 419-32.

2. R. Collins et al., The Motion of Large Gas Bubbles Rising Through Liquid Flowing in a Tube, J. Fluid Mech. 89 (1978) 497-514. 
3. Duong Ngoc Hai, Nguyen Duy Thien and Ha Cong Tu, Model Study of the Vertical Flows of Intermittent Gas Lifting, Proc. of The $5^{\text {th }}$ International Conf. on Multiphase Flows-ICMF2004. Yokohama, Japan, 2004.

4. Gossell Steve, Intermittent GasLift Manual. Part: Instructions for Spread Sheet Pilot Valve Specifications, and Section 6 - WFM-14R Pilot Operated GasLift Valve, Camco, 1998.

5. G. A. Hughmark, Film Thickness, Entrainment and Pressure Drop in Upward Annular and Dispersed Flow, AIChE J. 19 (5) (1973) 1062-64.

6. A. B. Neely, J. W. Montgomery and J. V. Vogel, A Field Test and Analytical Study of Liquid Loss in Intermittent Gas Lift, Soc. Pet. Eng. J. 14 (1974) 502-12.

7. Z. Schmidt et al., Hydrodynamic Model for Intermittent Gas Lifting of Viscous Oil, J. Pet. Tech. 36 (1984) 475-85.

8. I. H. Shames, Mechanics of Fluids, McGraw-Hill, 1992.

9. G. B. Wallis, One Dimensional Two-Phase Flow, McGraw-Hill, 1969.

Received June 25. 2007.

\section{NÂNG CHẤT LÒNG GIÁN ĐOẠN DÙNG KHÍ TRONG ỐNG ĐƯNG}

Bài báo trình bày một số kết quả nghiên cứu thực nghiệm và lý thuyết dựa trên mô hình vật lý - toán trong ống đứng để xác định các thông số vận hành chính khi khai thác chất lơng (dầu thô) bằng công nghệ nâng chất lơng gián đoạn dùng khí. Mô hình lý thuyết được xây dựng và hiệu chỉnh dựa trên kết quả thực nghiệm trên mô hình vật lý. Mô hình toán cho phép xác định được sản lượng chất lỏng có thể khai thác tùy thuộc vào lưu lượng và áp suất khí nén. Mô hình cũng chỉ rõ sự ảnh hường của khối lượng chất lơng ban đầu trong ống và tính chất của chất lỏng tới khả năng nâng đãy chất lỏng bởi khí nén gián đoạn. Để nghiên cứu ảnh hường tính chất vật lý nhiệt của môi trường, đã tiến hành thí nghiệm với 2 hệ lơng-khí. Mô hình toán học được giải bằng phương pháp số. Kết quả nghiên cứu được áp dụng cho điều kiện thực tế. 